\title{
Research on Community Care Mode for the Elderly Based on Enterprise
}

\author{
Fan Xinhe \\ School of Business \\ Yunnan University of Finance and Economics \\ Kunming, P. R. China \\ 1372735837@qq.com
}

\author{
Jia Jia \\ School of Public Management (SPM) \\ Yunnan University of Finance and Economics \\ Kunming, P. R. China \\ 564136249@qq.com
}

\begin{abstract}
Now elderly care has become an unavoidable problem in aging China society. Family planning has collapsed traditional family pension mode in China, and institution pension mode does not conform to the traditional concept of Chinese old people. Community care not only conforms to the traditional concept of Chinese old man, but also can effectively reduce the cost of pension, thus it maybe become the future direction of development. This paper has observed the representative of community care modes in our country, which is called Shanghai Jing'an mode, and analyzed the problems existing in the mode. Then accordingly this paper proposed community care mode based on enterprise, which was considered to better solve the main problems existing in the current community endowment mode.
\end{abstract}

Keywords-Community Care Mode for the Elderly; Enterprization; Pension; Jing'an Mode

Nowadays China has entered the aging society. The implementation of the family planning policy for a long period has brought about the emergence of a unique "4 $+2+1$ " family structure mode, which makes traditional family pension mode collapse in China. At the same time, because of the delay of the construction of China pension institutions and the influence of China traditional culture, institution pension mode is difficult to become the mainstream of social pension. Then, how to provide pension services in China?

The Twelfth Five Year Plan of national basic public service system, promulgated in 2012, proposed to establish a sound pension service system. The one encourages home care, and expands community pension service function, and enhances the service ability of public pension agencies, and encourages guiding social capital to participate in constructing and running pension agencies by all means, for example, public construction and private operation, or private construction and public help. This document put forward the development direction of pension services in our country and made community care come to the fore.

\section{INTRODUCTION}

About community care, the western countries in 1960s first proposed the theory of "Aging in Place". The British attempted to carry out community care for the elderly after intensive study. By 1980s, the mode became popular in Western countries and related research also became more and more deeply.

In 1989 British government issued a white paper on social welfare, in which community care referred to the elderly were looked after at home by community care agency. P. Schopflin (1991) proposed that community care referred to the elderly were cared for and installed through non- institutional ways, including family meals, cleaning, personal care, day care etc. At present, foreign scholars generally believe that community care services should include daily life care, medical health care, family caregiver support, spiritual and cultural communication etc.

After the researches, the domestic scholars, including Zhang Minxing, (2008), Chen Ping (2010), Gao Xiaolu (2012), Yang Jianjun (2012), all thought community care mode would become the main pension mode in China. Mu Guangzong (1999) thought community care was a pension system that the aged lived at home and accepted care services provided by community. This system combined home care with social care and needed government support. Most of the scholars thought that the needs of the elderly for community care services included daily life care, health care, spiritual comfort, legal rights, recreational activities, emergency rescue etc. For pension services providers, domestic scholars tended to welfare pluralism, which advocated establishing a multiple pension service system comprising government, families, enterprises, non-profit organizations. For the existing problems in the community care mode, scholars summed up from four aspects: money, people, service content and the role of government.

On the basis of the domestic and foreign researches, we believe that developing community care has become the consensus of scholars at home and abroad, and community care at least need to provide these services for the elderly, such as daily life care, medical and health care, spiritual comfort, cultural and recreational activities. But in our country there are still many problems which need to be solved about community care mode. It is important to study this mode. 


\section{PRESENT CONDITION OF COMMUNITY CARE SERVICE IN CHINA}

\section{A. The concept and advantages of community care service for the elderly}

Community care refers to a kind of pension mode that the elderly live at home and the pension services are provided by all kinds of social forces of community centered. That means the old people will not be separated from the family and the community lived, and at the same time they can also enjoy a variety of care services provided by the community. In many cases, Community care is also known as home-based care.

The theory of social embeddedness is the theoretical basis for the development of the community endowment. The theory put forward that any person is not isolated, and everyone is all embedded in a particular social structure and relationship network through which we can get social support and other social resources, such as information, emotion, and service. Although institution care mode can provide the perfect facilities and considerate care services for the elderly, it makes against the communication between the elderly and his relatives. So it easily makes the elderly feel a lack of emotion and abandoned by society and spirit needs do not be met.

Community care can effectively avoid the above problems. On the one hand, it conforms to the traditional concept of the elderly. According to a survey of pension wishes of the elderly by Ministry of Civil Affairs, more than $90 \%$ of old people still hoped to be cared for at home. In the community care mode, the elderly still live at home and do not have to leave the original living environment and social relations. They don't have to live in the dormitory of beadhouses, change their lifestyle and try to adapt to a new environment. They can still communicate with their relatives and friends frequently. Therefore they will not have a sense of social alienation. It is also convenient for their children to take care of them in their spare time. So the elderly's spiritual needs can be fully met. On the other hand, community care can also better meet the material needs of the elderly. Community care can adequately integrate and utilize the resources of family and community, which will greatly reduce the cost of pension. Professional services provided by the community pension service agencies can better guarantee the quality of life of the elderly. Thus the elderly can obtain the required pension services at a lower cost, which will eliminate his children's worry. Therefore, community care is conducive to the physical and mental health of the elderly. At present, community care has become the main pension way for the aged people in Europe, USA and other developed countries. It is also promoted actively in Japan and other countries.

\section{B. The main mode of community care in our country}

The research on community care mode for the aged in our country began in the 80 's of last century, which was a late start. At that time in order to solve the problem of lacking pension institutions, Dalian city launched the first community pension service system. After that Shanghai, Ningbo, Wuxi, Guangzhou and other cities also began to carry out related work. But at present this mode is still limited in the developed big cities, seldom in small and medium-sized cities.
Shanghai is the first city to enter the aging society in China, and is also one of the earliest cities to explore community care mode. So its mode is representative. In Shanghai the most representative community care mode is called Jing'an mode. There are two main forms about pension services provided in Jingan community. For the older people who can take care of themselves, encourage them to come out to the elderly activity room in community and accept pension service. And for the older people who can't take care of themselves and can't walk out from their home, send nursing staff to provide home services. The first form is to establish the day service center for the elderly in the community. Every morning the old people who have a good body come to day service center himself, chat here, rest, and have three meals a day. The staff will measure blood pressure for the elderly and the doctors who come from tertiary hospital will regularly come to have a physical examination. Thus the center can provide one-stop service for the elderly, including life care, health care, spiritual comfort, entertainment and other services. The second form is home services, which mean to provide one-to-one service in the elderly's home, including blood pressure measurement, rubdown, shampoo, and sending the old man to the hospital etc It should be said that Jingan mode is an earlier mode carried out in our country and also a more mature mode. It represents the high-end level of community pension services in China.

\section{THE EXISTING PROBLEMS OF COMMUNITY CARE MODE IN CHINA}

Although community endowment mode has been explored for a certain extent in cities in our country, and has reached a certain level in some developed areas, there are still many problems as follows about the mode.

\section{A. Lack community infrastructure}

To carry out the community pension service, we need to provide places for the elderly activities, such as the elderly activity room, fitness equipment, outdoor activities place etc. But in fact many residence communities lack of these facilities. If now the government comes forward to build, not only a huge investment, but also the adequate land will be an actual problem.

\section{B. Community care services are not comprehensive}

The current community care mode is mainly to provide general services, such as life care, catering services, so the services' breadth and depth all need expand. For example, the current health care services are mainly free blood pressure measurement, health knowledge spreading and mental health counseling, but recovery care, home diagnosis and other health services are very few. Another example is the cultural and recreational activities. Now the community service is mainly to provide the elderly with the place for their chatting and watching $\mathrm{TV}$, and lacks various cultural and recreational activities. 


\section{Professional skills and quality of community staff are still relatively poor}

In order to take good care of the elderly, community staff must grasp all kinds of knowledge, such as psychology, nursing, nutrition, and so on. But this is the most deficient ones for community staff at present. For example, in Jingan Temple Street community staff who provide nursing services is mainly more than 500 volunteers and some re-employed laid-off workers. So it is imperative to improve the professional level of community staff.

\section{Community care coverage is very low}

Even the developed cities like Shanghai can't guarantee the community care service. At present, Shanghai has established a pattern of 9073 pension services, which means that $90 \%$ of the elderly is family self-care, $7 \%$ of the elderly can get community care services, $3 \%$ of the elderly need choose institutional pension. Even if in Shanghai, the most economically developed city in China, only $7 \%$ of the old people can get community care services, not to mention the rest of the country.

\section{ESTABLISH COMMUNITY CARE MODE FOR THE ELDERLY BASED ON ENTERPRISE}

As shown above, obviously it is not appropriate to provide community care service for the elderly just by the government. First, the government does not have so much money to provide adequate community pension services and unable to meet the large needs. Secondly, the government is now streamlining the organization, so it is not in line with the direction of reform that the government organizes a large number of human resources to establish and operate the community service institutions. Finally, community care services provided by the government can easily lead to bureaucratic culture, low efficiency and other issues. Therefore, we think it is more in line with the development direction of China's pension services to establish community care mode based on enterprise for the elderly.

\section{A. Establishment ways}

In today's China society, because of the fierce competition and the impact of online shopping, a variety of social resources leave unused. There are two ways to establish community care institutions based on enterprise. One way is M\&A, which means large enterprises merger the various resources near community, such as shops on the verge of collapse, restaurants, community health service center, and establish own direct chain mechanism. Another way is integration, which means an enterprise dominates to integrate the above all kinds of idle resources and to establish an enterprise alliance together to provide community care service for the aged. The first way has a strong control, but needs plenty of money. The second approach does not require much investment, but requires a very high management capability. But no matter which kind of way, we can first pilot and then promote. Because integrating a variety of social idle resources, it can solve the problem of low community pension coverage in a short period. In order to effectively operate, enterprises will invest resources in the construction of the elderly activity room, fitness equipment and other infrastructure, which will solve the problem of community infrastructure to a large extent.

\section{B. Scope of service}

As a result of competition, enterprises will provide a variety of pension services and expand continuously as long as the elderly have the need. From daycare service, catering services, maintenance services, to the entertainment services (such as organizing to travel), the medical service, to one-to-one nursing until a variety of customized service, the enterprise all can provide. Moreover, the enterprise has the strength to communicate with hospitals, travel agencies, maintenance companies, food and beverage companies, and can organize these resources to provide comprehensive and thoughtful services for the elderly. This will solve the problem of scope of community care service.

\section{C. service personnel}

F Service personnel mainly rely on enterprise full-time staff. Enterprises will conduct professional training and strict management, so as to solve the problems of professional skills, quality and management of personnel. Because community care industry is a labor-intensive industry and it can accept a lot of labor, it also provides a good way to solve the problem of employment.

\section{D. charge problem}

Of course, for the implementation of community care mode based on enterprise, a lot of people worry about the charge problem and worry that the elderly cannot afford. In fact, the problem is not so serious. First, the enterprises' investment is not so much. Enterprises do not need to build a nursing home, and the elderly live in their own homes. Enterprises only need to provide day activities place and fitness facilities, etc. Other services provided can also be outsourced, or can be acquired by integrating the existing resources. For example, medical treatment can be outsourced to community hospitals, catering can be outsourced to several catering enterprises, and tourism can be outsourced to some travel companies, etc. Second, the investment can also be reduced from several aspects. Firstly, the government bears the expenses of community infrastructure and the corporates who make use of these facilities lower charge when pricing. Secondly, the government gives policy support to community service enterprises in water, electricity, heating, tax and credit, etc. Thirdly, the government reforms present tax system and establish a new personal income tax collection system considering a family's pension and nursery conditions. Thus the family pension payment ability will be strengthened. Fourthly, the government helps to purchase basic community care services for the poor old man who really cannot afford to pay the fees. When considering the intense competition between the enterprises, we believe the charge will not be a problem of preventing community care enterprises developing after having implemented these measures.

\section{CONCLUSION}

The establishment of community care mode based on enterprise is an inevitable outcome of the combination of aging 
society and Chinese traditional culture. Although the enterprises are the main builders, the government plays an important guide role. The government needs to play its unique role in the construction of community infrastructure, the development of support policies, tax reform, and transfer payments and so on. At the same time, the government should also play a watchdog role. It needs to formulate industry access standards and service standards and strengthen the supervision to ensure the community care enterprises to run in compliance. Of course, to give priority to the enterprises does not mean they should do everything. In fact we should play an important role in the government, non-profit organization and family to establish a diversified pension service system for the aged.

\section{ACKNOWLEDGMENT}

F. J. sincerely thank all the people who have helped and are helping us for their unselfish help, especially the ones who have helped us but not been mentioned because of the length of the paper.

\section{REFERENCES}

[1] Li Zhenni, Qin Xiaoting. "Research on the status quo and countermeasures of the urban community service for the aged-taking Shanghai City as an example". Theory Research, China, No 4, pp. 136138, June 2015. (in Chinese)

[2] [1] Li Xiaomei. "A review of domestic and foreign research on home care services". Journal of Chongqing College of Electronic Engineering, China, vol 22, No 4, pp. 72-75, July 2013. (in Chinese)

[3] Liu xiaojing, $\mathrm{Xu}$ hongbo. "Industrialized social security services in communities-a perspective of diversified welfares". Journal of Hebei Normal University/ Philosophy and Social Sciences Edition, China, vol 36, No 5, pp. 123-127, September 2013. (in Chinese)

[4] Zeng Yu. "The Path of Community Support: Specialization, Industrialization and Large-scale". Northwest Population Journal, China, Vol 29, No 3, pp. 38-41, June 2008. (in Chinese) 